\title{
6
}

\section{TURNING THE KEY}

\section{How the Pink Passkey Has Shaped the Landscape of (Un)Equal Opportunity for LGBT-Friendly Eldercare Provision in the Netherlands}

\author{
Roos Pijpers
}

\section{Introduction}

Despite the attention to $\mathrm{LGBT}^{1}$ rights that has been achieved in the Netherlands, many older LGBT adults choose to hide their sexual orientation or gender identity out of fear of rejection by care professionals, neighbors, or care home residents (Leyerzapf et al. 2018; Willis et al. 2016). Indeed, people who openly express their sexual orientation or gender identity may be confronted with forms of bullying and prejudice (Pijpers 2020). As a result, older LGBT adults feel relatively unsafe in their neighborhoods (ibid.) and residential care homes (Leyerzapf et al. 2018).

Because of this vulnerable position, a number of initiatives have been taken to increase attention to sexual and gender diversity in eldercare. The most important of these is called the Pink Passkey [in Dutch: Roze Loper], a quality certificate for LGBT-friendly care provision. The certificate guarantees that care providers with a Pink Passkey pay attention to LGBT residents and try to make them feel welcome and at home. The Pink Passkey was developed in the city of Nijmegen, a medium-sized city in the southeast of the Netherlands, in 2007. The notion of 'passkey' was chosen to underline the idea that providers can be LGBT-friendly in various ways. Since then, interest in the initiative has spread around the country. By now, there are approximately 160 care spaces with a Pink Passkey, mostly in cities but increasingly also in rural areas.

The aim of this chapter is to offer a critical discussion about the contribution of the Pink Passkey to LGBT-friendly provision of housing, care, and services for older adults in the Netherlands. To this purpose, the next section presents an approach to care and the city inspired by work in care ethics, urban citizenship theory, and practice theory. This is followed by a methods section detailing the scope and limits of fieldwork activities. The subsequent two sections discuss, first, different ways in which the Pink Passkey recognizes and supports older LGBT adults as care receivers, and second, the socio-spatial inequalities shaped and reshaped by Pink Passkey activity between and within cities. 


\section{Conceptualizing the Pink Passkey as a Form of 'Doing' LGBT-Friendly Care}

The research literature on housing, care, and services for older LGBT adults has burgeoned in recent years. Attention has gone to, among others, their current and anticipated needs in these areas (see Addis et al. 2009; Westwood 2016). This literature suggests that many hope to be able to move to an LGBT-friendly care home someday, with some explicitly preferring an LGBT-specific care home. Other studies, however, have shown that most care providers do not pay sustained attention to sexual and gender diversity among residents and staff (Simpson et al. 2018; Willis et al. 2016). To analytically connect these care needs and care providing dimensions, the chapter draws on care ethics, a moral theory aiming to make "caretaking and caregiving activities appear in theory as they are in life" (Walker 2007: 84; see Thelen 2015; Tronto 1993, 2013). Care ethics understands care as a key concept of morality precisely because it foregrounds relations involving giving and receiving dimensions (Conradi 2020). Empirically, it focuses on recognition and support, calling attention to the needs of specific individuals or groups (ibid.), and associating these needs with their hidden experiences (Walker 2007).

This chapter takes inspiration from Joan Tronto's $(1993,2013)$ definition of care receiving, which entails the ability of people to respond to the care they receive. Ideally, the Pink Passkey does exactly this: enabling older LGBT adults as care-receiving subjects, able to respond to care. Unfortunately, research into their care-receiving experiences is difficult, since many current LGBT residents of care homes, born between the 1920s and 1940s and middle aged in the 1970s and 1980s when LGBT emancipation took off, have lived closeted lives. In the Netherlands, this problem is deepened by the fact that only people with advanced physical and cognitive impairments have access to care homes. As a consequence, even in care spaces with a Pink Passkey, older LGBT people may remain invisible, and their experiences hidden. For Tronto (2013), however, in case the (intended) care receivers are not able to respond to care, responses may be sought elsewhere.

By way of an alternative response to the contribution of the Pink Passkey to LGBT-friendly care for older LGBT adults, this chapter proposes a specific approach to care and the city. First, in this approach, following Tatjana Thelen (2015), the term 'care' is uncoupled from its inherently positive connotation and instead understood as a process with an open-ended outcome. Seen in this light, the Pink Passkey is not in and of itself an inclusive form of care; at best, it is a way toward (more) inclusive care, potentially able to improve on the social safety of care spaces. Second, I borrow the idea of a moral minimum of urban citizenship coined by Bart van Leeuwen (2010). This moral minimum entails a certain degree of indifference toward other citizens (residents) that can be acceptable in fleeting encounters in everyday urban life settings and by extension, everyday life in the care home. In order to meet the moral minimum, there should be an attentiveness to other citizens (residents) as respectable persons, and to their basic needs, especially non-discrimination. There need not be an explicit attentiveness to people's social identity, including, if we continue the analogy, their LGBT identity. Pink Passkey places that surpass this moral minimum do, to varying degrees, recognize LGBT identities and support needs associated with these identities.

Starting from care as a process that should meet a moral minimum of urban citizenship, I proceed by situating care in the context of the city. This is done by focusing on care practices-the specific and more generic activities associated with particular forms of care (Tronto 
1993, 2013; see Thelen 2015; Walker 2007). A focus on care practices helps to understand how care is 'done,' as part of, and alongside, a meshing of other social and spatial practices (Reckwitz 2002; Schatzki 2002). In this case, this means we can hope to know more about what the Pink Passkey contributes to inclusive care by looking at the way it is 'done,' that is, how it is implemented in care homes, and how and where people are reached. Here, in line with one of the key ambitions of care ethics (Tronto 1993), I am interested in how care practices blur the boundaries between the (relatively) private realm of the care home and the wider urban aging environments in which care homes are embedded. Focusing on care practices is also useful in shedding light on the socio-spatial inequalities associated with the Pink Passkey. For practice theorists Elizabeth Shove, Mika Pantzar, and Matt Watson (2012:135), "the emergence, persistence and disappearance of practices [...] generates highly uneven landscapes of opportunity, and vastly unequal patterns of access." With the geographical distribution of a practice across (urban) space, power relations, ideas, values, identities, and so forth are reconfigured, redressing or reproducing inequalities or creating new ones (Nicolini 2007). Differences in availability of Pink Passkey places, and in the ways in which Pink Passkeys are implemented, then speak to inequalities in how LGBT identities are recognized and supported (Westwood 2016). Finally, in this approach to care and the city, morality is seen as a shared understanding of local actors engaged in a practice (Schatzki 2002; see Walker 2007). This implies that morality is also situated in the complexities of everyday urban life. Accordingly, there is the scope to transform care practices that are found to create or reproduce inequalities in mindful encounters of actors at the level of everyday urban spaces (Williams 2017).

Through attuning care to the complexities of everyday life in the city in the way proposed here, I am able to reflect on the Pink Passkey as a form of 'doing' LGBT-friendly care, and on what it 'does' for LGBT aging within care spaces and the urban spaces in which these are situated.

\section{Research Methods}

This reflection is based on knowledge gained about the Pink Passkey in the course of a broader research project about responsiveness to sexual and gender diversity in the provision of housing, care, and services for older people in Dutch cities. The project consists of subprojects on the experiences of older LGBT adults aging in place (Pijpers 2020) and on responsiveness developed by local governments and individual providers (see Honsbeek and Pijpers 2020). The interest in the Pink Passkey emerged out of these subprojects. Participant observations, semi-structured interviews, and document analysis were used to study manifestations of care practices, such as actors and activities involved, their interdependencies, and underlying ideas (Bueger 2014).

Through the fieldwork of my PhD student, Krystel Honsbeek, I was able to 'zoom in' (Nicolini 2010) on care provision within a residential care space with a Pink Passkey. Krystel frequented this place, which is part of a large provider of residential and home care in the city of Den Bosch, for a period of one year. In addition to observations during personal caregiving and group activities, Krystel conducted interviews with staff ranging from management and nurses to volunteers and activity leaders and attended meetings of two organization-wide diversity teams.

'Zooming out' (ibid.) of this particular residential setting, I followed connections between places where a Pink Passkey is implemented or discussed or has achieved something, either 
intended or unintended. In particular, I considered the effects of the Pink Passkey in broad terms of increasing availability of (some form of) LGBT-friendly care meeting or surpassing the moral minimum. I spoke to representatives of eight organizations with a Pink Passkey, including one community care provider and one home care provider. Further, I observed during two activities at two other organizations with a Pink Passkey, which allowed me to talk to several participants and staff members. From early 2017 onwards, I have been in contact with six people affiliated with the Pink Passkey and four experts who can be commissioned for policy advice or staff trainings. Finally, I used one interview with a client of a residential care organization from the broader project.

To ensure coherence within and between the 'zooming in' and 'zooming out' parts of the research, I used so-called 'verification strategies' (Morse et al. 2002). Notably, these strategies entail going back and forth between findings and theoretical literature, contacting old respondents and reaching out to new respondents to crosscheck findings, and continuously rethinking the fit between findings and the overarching aims of the chapter.

\section{The Pink Passkey: Surpassing a Moral Minimum of Urban Citizenship?}

At first, care providers received a Pink Passkey relatively easily. It was awarded in a playful manner, but with a serious undertone, by a group of activists from the Nijmegen chapter of COC Netherlands, one of the oldest LGBT advocacy organizations in the world. This group was part of a monthly meeting of aging gay men who started to share stories of friends who had found themselves in unsafe care settings. In those days, it was seen mostly as an incentive for providers with a general interest in LGBT issues. Since then, the Pink Passkey has professionalized in two ways. First, it has evolved into a quality certificate: In order to obtain a Pink Passkey, providers now need to go through an auditing procedure every three years (Meijsen 2016). Second, it is backed by an elaborate description of the practical steps underpinning the Pink Passkey as a social intervention (Linschoten and Boers 2014; Meijsen 2016) and an evaluation report (Kluit 2016).

The evaluation report (ibid.) shows that it has contributed to knowledge acquisition and awareness about sexual diversity in care organizations. Slowly but surely, the visibility of older LGBT adults within organizations with a Pink Passkey is increasing, although the numbers of visible elderly remain small. Activities organized within the framework of the Pink Passkey help to create and maintain tolerance toward older LGBT adults (see Leyerzapf et al. 2018). However, this tolerance is partly also seen as a symbolic improvement, which either masks an ongoing disinterest and misunderstanding among the majority of heterosexual residents or lasts for a brief period of time only (Kluit 2016). Hence, an older LGBT individual may opt for a Pink Passkey place based on false expectations about tolerance and non-discrimination, and/or false assumptions about the situation in other places being worse (ibid.). Here, people compare an imagined LGBT-friendliness of Pink Passkey places with an imagined unfriendliness of places without a Pink Passkey (see also below).

My fieldwork suggests that Pink Passkeys are broadly applied in one of three ways. The first is to use the Pink Passkey mostly symbolically. This means providers refer to it in publications, such as websites and newsletters, but do not engage in further action or activities. Arguably, the symbolic way of using the Pink Passkey comes with a high risk of achieving only symbolic improvement, hence of not meeting the moral minimum. 
The second way is to regularly organize activities in the framework of the Pink Passkey and pay additional attention to sexual and gender diversity on 'special occasions,' such as Pride Week and International Coming Out Day. Usually, these activities are open to visitors from the wider neighborhood. Some providers offer training sessions to raise awareness and enhance competencies of staff. Such sessions are offered irregularly, as part of a 'special occasion' program or in-house day training program. This way of applying the Pink Passkey is what the initiators realistically aim for (Linschoten and Boers 2014).

The third way is to try and embed the Pink Passkey in organizational policies and daily care practices. The residential care space in Den Bosch, where in-depth qualitative research was done (see above) for example, has a sustained commitment to sexual diversity, articulated in formal vision and policy documents, and upheld by a diversity team. As a result, attention to sexual and gender diversity is perceived as 'normal' by a growing group of residents, caregivers, and volunteers and slowly but surely is normalized in daily work practices as well (Honsbeek and Pijpers 2020).

\section{The Pink Passkey Shaping (Urban) Inequalities in LGBT-Friendly Care Provision}

\section{Availability of Pink Passkey Care Spaces}

As Figure 6.1 shows, the Pink Passkey still, by and large, is an urban phenomenon, although Pink Passkey activity in semi-urban and rural places is growing. Roughly 50 out of a total of 160 Pink Passkey places registered (RozeZorg 2020) are located in Amsterdam. The establishment of COC Netherlands in 1946 made Amsterdam the 'gay capital' of the Netherlands (Zebracki and Maliepaard 2012). Over the years, Amsterdam has attracted many LGBTidentifying individuals who are now middle-aged or aging. The map also shows concentrations of Pink Passkeys in Utrecht and Nijmegen, cities with a strong LGBT activist base rooted in the 1970s and 1980s liberation movements. In Amsterdam, Utrecht, and Nijmegen, these pre-existing geographies and histories resonate in the visibility and advocacy skills of the local LGBT community. Nevertheless, overcoming heteronormative views has been a real struggle, with providers claiming there are no lesbian or gay clients or resorting to a 'sameness' or 'one-size-fits-all' approach (Simpson et al. 2018; Westwood 2016). In recent years, Pink Passkey activity has increased in cities without a strong activist base, such as Den Bosch, as a result of equally difficult lobbying processes (Honsbeek and Pijpers 2020). Figure 6.1 further shows that there are fewer Pink Passkey places in the northern provinces, where local LGBT communities are still struggling to access care organizations (Pink Ambassador of the Province of Groningen, personal communication, April 2018). The same applies to providers with a religious background. In Nijmegen, the board and client panel of a Catholic care home for Dominican Sisters and laypeople from the surrounding neighborhood explicitly rejected meeting requests from local Pink Ambassadors (former member of client panel, personal communication, August 2019). Care providers with a religious background can be found all over the country, in the Catholic south and the Protestant north, in cities and in rural areas. In some rural areas, however, such a provider may be the only nearby option.

Also, inequalities exist within cities, that is to say, between the ways in which the Pink Passkey is applied in care spaces. In Amsterdam, locations that received one earlier organize more activities and outreach, even to the extent that they draw participants who actually live in other Pink Passkey places belonging to the same provider (participants, personal 


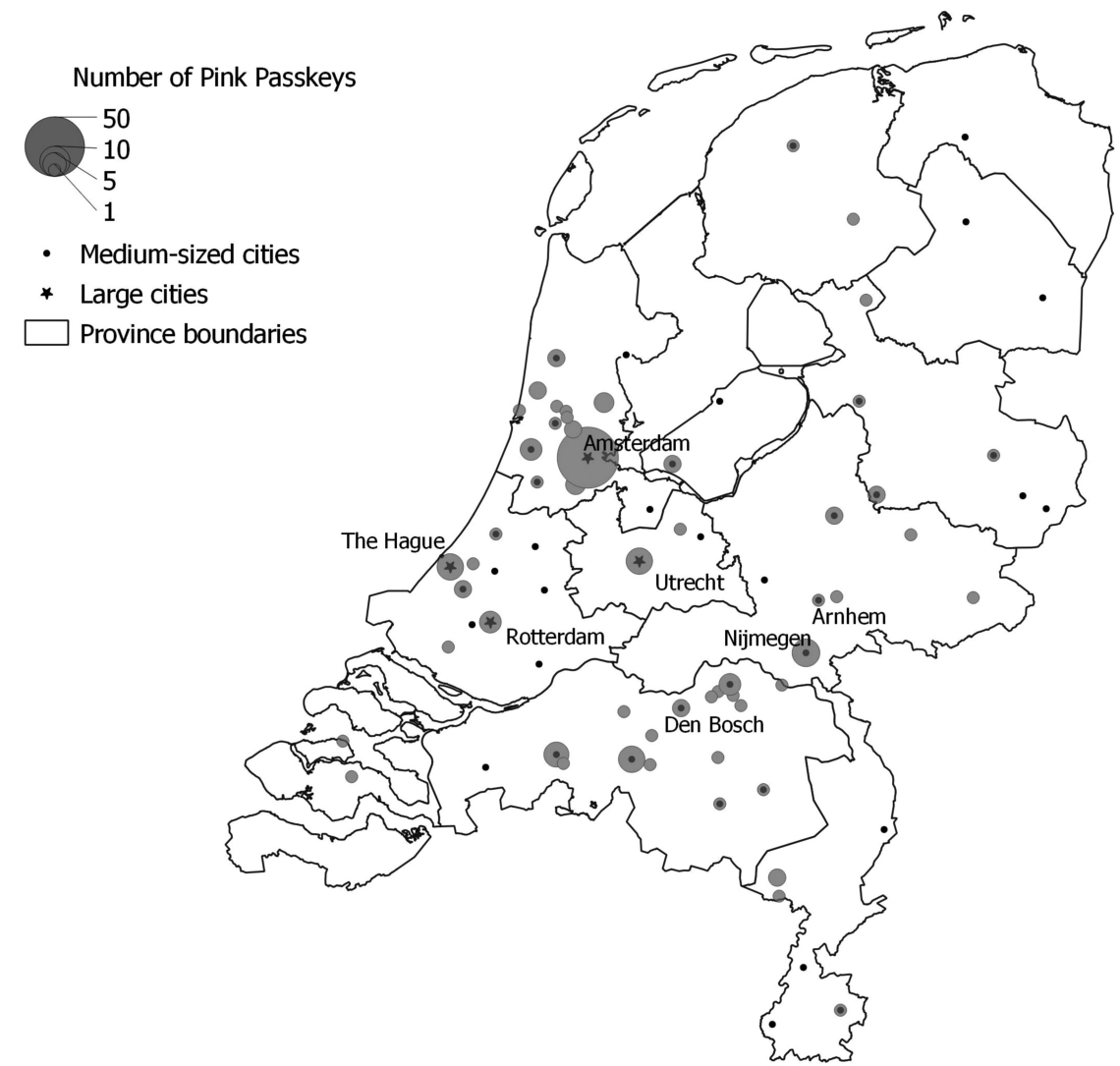

FIGURE 6.1 Geographical distribution of Pink Passkey activity. Data provided by RozeZorg (https://rozezorg.nl) [Accessed June 2020]. Source: Roos Pijpers, 2020.

communication, July 2019). At the very least, this suggests that LGBT-friendly care practices developed in one place are relatively sticky, and new places have to be phased in. Alternatively, this could be understood as an unintentional yet possibly convenient bundling of Pink Passkey activity in only a handful of places, which may suit older LGBT adults in other parts of the city as long as the moral minimum in the place where they live is met.

A third inequality is found in community care settings. At present, still only about a dozen Pink Passkeys have been awarded to home care and day care divisions of organizations, mostly in Amsterdam and locations near Amsterdam, as well as in several other medium-sized cities (RozeZorg 2020). At the same time, the number of older LGBT adults aging in place is growing (Pijpers 2020). Since home care and day care divisions usually service some but not all neighborhoods in a city, many older LGBT adults aging in place do not have the ability to choose a provider with a Pink Passkey.

\section{Suburban Aging Environments}

In recent years, a number of prestigious housing projects for middle-aged and older LGBT people have opened their doors, often voicing the ambition to provide some form of informal 
care and support for each other. For a short overview, see work by Sue Westwood (2016). Apparently, the idea of living together is appealing: The online survey published by outForever, an Amsterdam-based citizen initiative, available since 2006, shows this is a preferred way of (future) housing for LGBT people (outForever 2020). Underlying this preference is a range of more subtle motivations (Westwood 2016). Some people wish to avoid perceived shortcomings of mainstream forms of housing and care, others wish to create a space of solidarity and support, while some gay men wish to avoid being "a minority-within-a minority" (ibid.: 69). However, the availability of LGBT-specific housing projects is limited, as they take a long time to realize and effectively offer space to a limited number of people, which results in long waiting lists (Gambold 2017). Furthermore, accessibility of LGBT-specific housing projects may be limited due to income issues. The housing project Roze Hallen (2020), for example (see Figure 6.2), located in a highly gentrified area in Amsterdam, has owner-occupied apartments affordable for only a select group of individuals and couples. In sum, it can be argued that special housing projects may reinforce rather than redress the spatial inequalities in LGBT-friendly housing options (Westwood 2016). It is realistic to assume

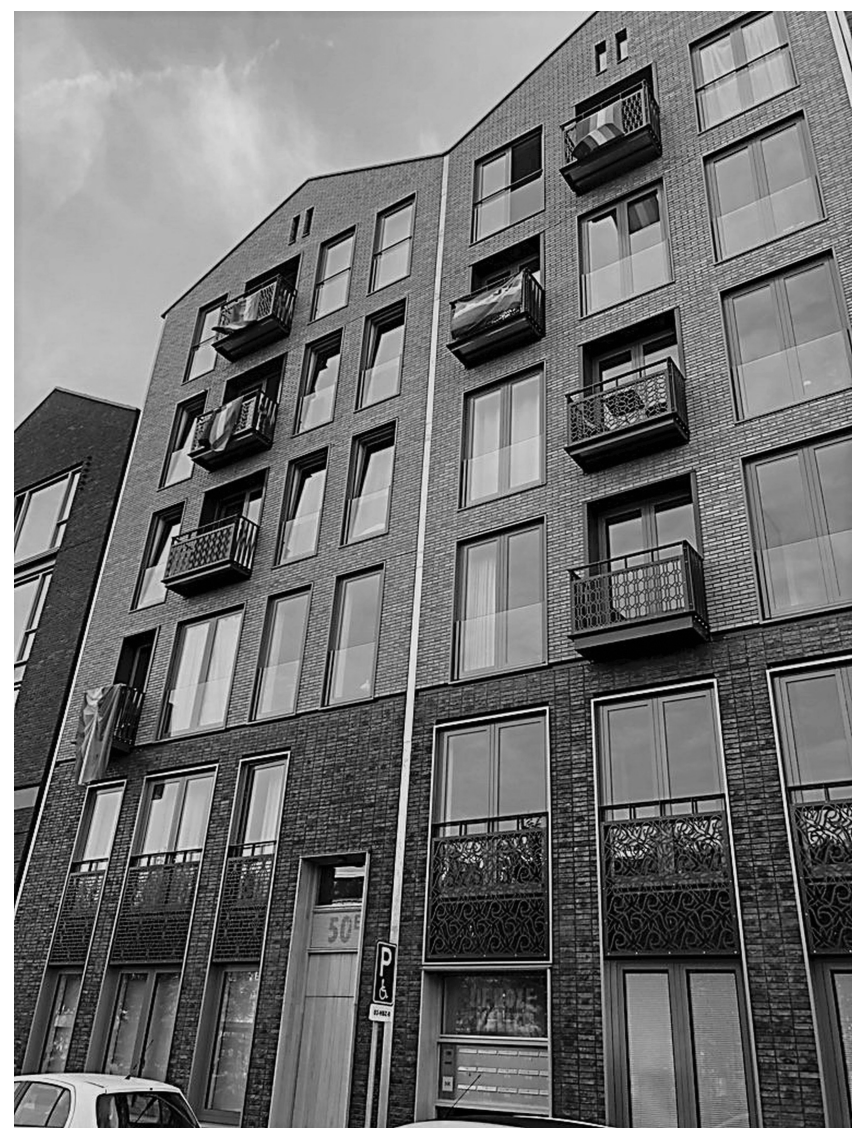

FIGURE 6.2 Rainbow flags at Roze Hallen housing project, Amsterdam Oud-West area. Source: Josée Rothuizen, 2018. 
that the vast majority of LGBT people currently in their fifties, sixties, and seventies will age, eventually with care and services, in 'ordinary' aging environments in cities, semi-urban and also rural areas.

Whereas the queering of central urban spaces is a key concern of local LGBT policies, there is usually no mention of ordinary living environments, where Pink Passkey places offer the only visible signs of respect for and openness to LGBT lifestyles. Arguably, the most powerful of signs is the rainbow flag (see Figure 6.3), which may be hoisted at the award ceremony or during special occasions. In addition, there are regular meeting activities, such as the ones where I observed. These activities attract older LGBT adults living in the wider neighborhood and even from places further away (participants and activity leaders, personal communication, July and October 2018; see also Honsbeek and Pijpers 2020; Kluit 2016). In fact, the most frequent visitors are people from the neighborhood (activity leader, personal communication, July 2018). Possibly, being a frequent visitor of meeting activities in Pink Passkey places may serve to lower the mental threshold to relocate to one of those places someday (see Kluit 2016). At least one resident of the Den Bosch care home has stated to have opted for this place because of the Pink Passkey (Honsbeek and Pijpers 2020).

\section{Imagined Urban Geographies of LGBT-Friendly Care Provision}

Under the surface of the real inequalities in the availability of Pink Passkey places, there appear to be 'imagined geographies' of LGBT-(un)friendliness, invoked by exaggerated contrasts between places (Baker and Beagan 2015). The situation in the northern provinces, for example, is sometimes cast in terms of 'lagging behind' and 'lacking potential' compared to cities such as Amsterdam and Nijmegen (Pink Ambassador of the Province of Groningen,

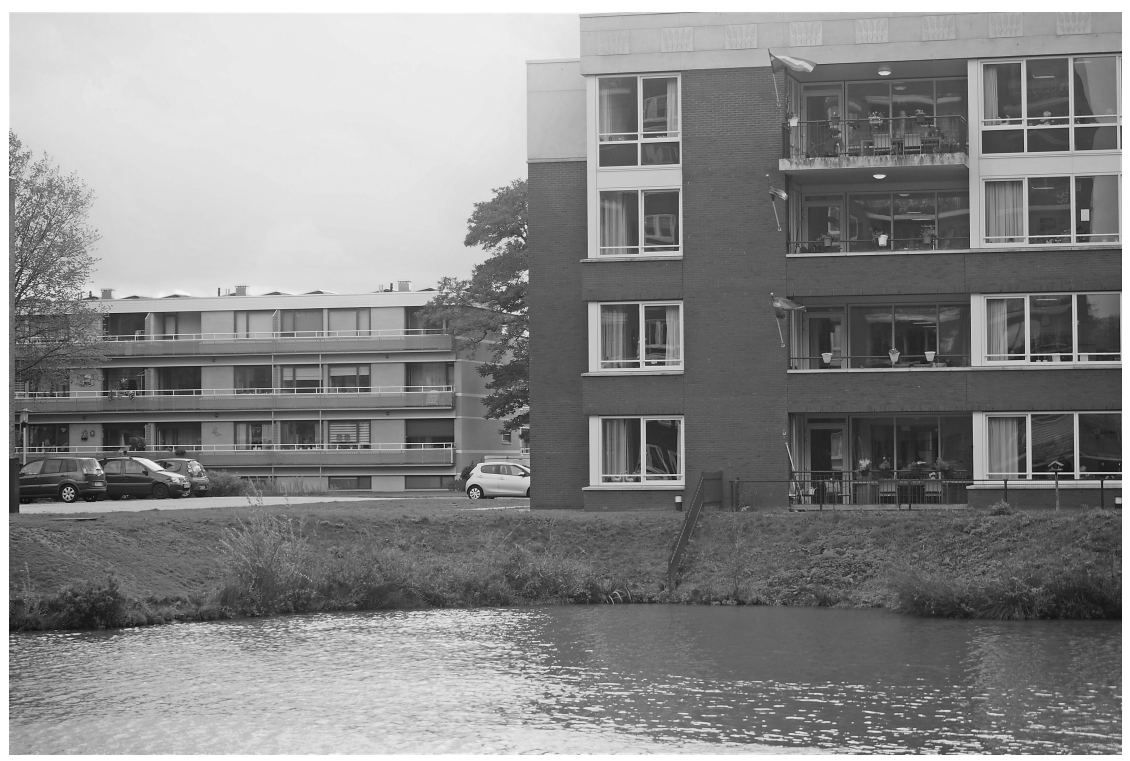

FIGURE 6.3 Rainbow flags at care home for older people with intellectual disabilities, Nijmegen Hatert area. Source: Daphne Hoekstra, 2020. 
personal communication, April 2018). Somewhat more unexpectedly, imagined geographies also emerged in an otherwise all too familiar case of urban rivalry.

Increasingly, as mentioned above, the Pink Passkey is also awarded to community care organizations. In the Netherlands, contrary to residential and home care organizations, these community care organizations are largely funded through local governments. In the city of Arnhem, just 20 kilometers north of Nijmegen, a community care provider is receiving funding from the national government for urban LGBT emancipation policies to pay for its Pink Passkey (activity leader, personal communication, June 2017; independent expert, personal communication, June 2019). The fact that there was a community care provider with a Pink Passkey in Arnhem first provoked a similar provider in Nijmegen to rush into a discussion about obtaining a Pink Passkey as well. Nijmegen and Arnhem are considered urban rivals by inhabitants of both cities and outsiders alike, with Nijmegen priding itself on its long tradition in LGBT emancipation, triumphing over Arnhem in this respect. In the end, however, no Pink Passkey was obtained precisely because of this tradition: In Nijmegen, funding is divided among many groups and initiatives liaised with the LGBT community, and not enough could be earmarked to support a continued Pink Passkey trajectory.

After this decision, however, the community care provider took the initiative of bringing together residential and home care providers in Nijmegen in a local working group. This group now organizes city-wide learning events on the life histories and care needs of older LGBT adults. These events are visited by caregivers working with older people in neighborhoods, private homes, and residential care homes. Inspired by the Pink Passkey, the group is an example of how ideas about LGBT-friendly care are shared and gradually find their way into the complexities of everyday life in the city.

\section{Conclusion}

In the last decade, the Pink Passkey has transformed from a sympathetic urban grassroots initiative into a professional quality mark with a strong symbolic character.Yet, it targets a group of care receivers that is still partly invisible and may in part wish to remain so. This makes ascertaining if, how, and how many older LGBT adults are helped through the Pink Passkey very difficult, if not unfeasible. Perhaps a more meaningful question to ask, therefore, is how the Pink Passkey can be 'turned,' that is to say, how it can be put to use in the complexities of daily life in urban aging and care environments. In this chapter, the Pink Passkey was conceptualized as a form of 'doing' LGBT-friendly care, which, like a true passkey, fits specific care spaces and local histories and geographies of LGBT activism and policy making. Aiming to bring to light older LGBT adults as care receivers who, albeit still largely invisible in these care spaces, are able to experience a basic sense of social safety, I took recourse to the idea of a moral minimum of urban citizenship. Based on the preliminary findings of ongoing fieldwork, it is safe to say that 'turning the key' offers older LGBT adults some (more) recognition and support to better resist heteronormative views in which LGBT identities are ignored or misrepresented.

The Pink Passkey was shown to curb socio-spatial inequalities in LGBT-friendly care provision but also to create new inequalities, through real and imagined urban geographies connecting care spaces and wider urban aging environments. In some ways, the Pink Passkey lives up to the care-ethical promise of redrawing the boundaries between (predominantly) private and public realms. Compared to the acceptable degree of indifference produced in fleeting encounters, as specified in the moral minimum, the Pink Passkey as an active 'doing' is a result 
of more organized encounters between policy makers, activists, and caregivers, contingent upon local conditions (Williams 2017). These organized encounters enable an ongoing reflection and sharing of ideas, and lends it a moral dimension, too. Of course, the Pink Passkey is only one example of a myriad social interventions that have started from specific spaces in the city targeting a particular group of vulnerable or invisible care receivers and are now trickling down as dynamic urban care practices. What these examples serve to show, more than anything, is an urbanization of care that may not in itself be new but is increasingly made visible in care-sensitive approaches to the city.

\section{Note}

1 LGBT stands for lesbian, gay, bisexual, and transgender. In academic and policy texts, increasingly the longer acronyms LGBTQ (Q stands for queer), LGBTI (I stands for intersex), LGBTQI or LGBT $+(+$ stands for a diversity of sexual and gender identities other than LGBT) are used. This chapter still uses the shorter acronym LGBT as it better represents the terms the respondents in my research prefer or identify with. In fact, some respondents criticize the 'newer' terms for being difficult to understand for heterosexual cisgender majority populations (Pijpers 2020).

\section{References}

Addis, S., Davies, M., Greene, G., Macbride-Stewart, S. and Shepherd, M. (2009) The Health, Social Care and Housing Needs of Lesbian, Gay, Bisexual and Transgender Older People: A Review of the Literature. Health and Social Care in the Community 17(6): 647-658.

Baker, K. and Beagan, B. (2015) 'Unlike Vancouver ... Here There's Nothing': Imagined Geographies of Idealized Health Care for LGBTQ Women. Gender, Place \& Culture 23(7): 927-940.

Bueger, C. (2014) Pathways to Practice: Praxiography and International Politics. European Political Science Review 6(3): 383-406.

Conradi, E. (2020) Theorising Care: Attentive Interaction or Distributive Justice? International Journal of Care and Caring 4(1): 25-42.

Gambold, L. (2017) Outliers Aging Abroad. Paper presented at the 14th IMISCOE Annual Conference, Erasmus University Rotterdam, Rotterdam, 28-30 June.

Honsbeek, C.G. and Pijpers, R.A.H. (2020) Aandacht voor Roze Ouderen bij BrabantZorg: Beleid,Activiteiten en Dagelijkse Zorg [Online]. Nijmegen: Radboud University Nijmegen. Available at https://rozeoud erenzorg.files.wordpress.com/2020/10/roze-ouderen-bij-brabantzorg_radboud-universiteit.pdf [Accessed 16 March 2020].

Kluit, M. (2016) Rapportage Bewonersevaluatie Roze Loper [Online]. Amsterdam: Consortium Roze 50+. Available at https://mijnsinziens.com/wp-content/uploads/Rapportage_bewonersevaluatie_Roze _Loper.pdf [Accessed 16 March 2020].

Leyerzapf, H.,Visse, M., De Beer, A. and Abma, T.A. (2018) Gay-Friendly Elderly Care: Creating Space for Sexual Diversity in Residential Care by Challenging the Hetero Norm. Ageing \& Society 38(2): 352-377.

Linschoten, M. and Boers, H. (2014) Handboek De Roze Loper: Een Methode om Aandacht voor Seksuele Diversiteit in de Zorg te Vergroten [Online]. Amsterdam: Consortium Roze 50+. Available at: https:/ /www.roze50plus.nl/wp-content/uploads/2020/01/Roze-Loper-handboek-digitaal.pdf [Accessed 11 April 2019].

Meijsen, E. (2016) De Roze Loper: Interventiebeschrijving. Utrecht: Movisie.

Morse,J.M., Barrett, M., Mayan, M., Olson, K. and Spiers, J. (2002) Verification Strategies for Establishing Reliability and Validity in Qualitative Research. International Journal of Qualitative Methods 1(2): 13-22.

Nicolini, D. (2007) Stretching Out and Expanding Work Practices in Time and Space: The Case of Telemedicine. Human Relations 60(6): 889-920. 
Nicolini, D. (2010) Zooming In and Out: Studying Practices by Switching Theoretical Lenses and Trailing Connections. Organization Studies 30(12): 1391-1418.

outForever (2020) outForever: Wonen voor een Nieuwe Generatie Homomannen en Lesbische Vrouwen [Online]. Available at: www.outforever.nl [Accessed 11 April 2019].

Pijpers, R.A.H. (2020) Experiences of Older LGBT People Ageing in Place with Care and Support: A Window on Ordinary Ageing Environments, Homemaking Practices and Meeting Activities. Sexualities. https://doi.org/10.1177/1363460720936471.

Reckwitz, A. (2002) Toward a Theory of Social Practices: A Development in Culturalist Theorizing. European Journal of Social Theory 5(2): 243-263.

Roze Hallen (2020) Roze Hallen [Online]. Available at www.rozehallen.nl [Accessed 28 January 2020].

RozeZorg (2020) RozeZorg: Aandacht voor Seksuele Diversiteit [Online]. Available at www.rozezorg.nl [Accessed 28 January 2020].

Schatzki, T.R. (2002) The Site of the Social: A Philosophical Account of the Constitution of Social Life and Change. University Park: Pennsylvania State University Press.

Shove, E., Pantzar, M. and Watson, M. (2012) The Dynamics of Social Practice: Everyday Life and How It Changes. London: Sage Publications.

Simpson, P., Almack, K. and Walthery, P. (2018) 'We Treat Them All the Same': The Attitudes, Knowledge and Practices of Staff Concerning Old/er Lesbian, Gay, Bisexual and Trans Residents in Care Homes. Ageing \& Society 38(5): 869-899.

Thelen, T. (2015) Care as Social Organization: Creating, Maintaining and Dissolving Significant Relations. Anthropological Theory 15(4): 497-515.

Tronto, J.C. (1993) Moral Boundaries: A Political Argument for an Ethic of Care. New York: Routledge.

Tronto, J.C. (2013) Caring Democracy: Markets, Equality, and Justice. New York: New York University Press. van Leeuwen, B. (2010) Dealing with Urban Diversity: Promises and Challenges of City Life for Intercultural Citizenship. Political Theory 38(5): 631-657.

Walker, M.U. (2007) Moral Understandings: A Feminist Study in Ethics. Oxford: Oxford University Press.

Westwood, S. (2016) LGBT^ Ageing in the UK: Spatial Inequalities in Older Age Housing/Care Provision. Journal of Poverty and Social Justice 24(1): 63-76.

Williams, M.J. (2017) Care-Full Justice in the City. Antipode 49(3): 821-839.

Willis, P., Maegusuku-Hewett, T., Raithby, M. and Miles, P. (2016) Swimming Upstream:The Provision of Inclusive Care to Older Lesbian, Gay and Bisexual (LGB) Adults in Residential and Nursing Environments in Wales. Ageing \& Society 36(2): 282-306.

Zebracki, M.M. and Maliepaard, E. (2012) Amsterdam Gay Capital. Geografie 21(1): 24-25. 